MATEC Web of Conferences 12, 04021 (2014)

DOI: $10.1051 /$ matecconf $/ 20141204021$

(C) Owned by the authors, published by EDP Sciences, 2014

\title{
Automotive stamped part fatigue design
}

\author{
Mélanie Caudoux ${ }^{1}$, Matteo Luca Facchinetti ${ }^{2}$ and Renaud Raynal ${ }^{2}$ \\ ${ }^{1}$ Apprentice at PSA Peugeot Citroën, Chassis System Engineering, 78140 Vélizy Villacoublay, France \\ ${ }^{2}$ PSA Peugeot Citroën, Chassis System Engineering, 78140 Vélizy Villacoublay, France
}

\begin{abstract}
Fatigue design of automotive axle parts is of prior concern because of these are high safety parts and they are expected to drive the overall vehicle mass reduction. In this framework, the stamping process is widely used to form axle parts, before assembling them by welding. Consequently, the mechanical and physical characteristics of the blank sheet are modified, having a strong influence on the fatigue behavior. In this paper, we address the consequences of the stamped process on the fatigue design and how they may be effectively taken into account in the automotive industry. Actually, the coupling between the stamping process and the fatigue design is under development at PSA Peugeot Citroën Company since several years. Such an analysis deals with some major topics: thickness variation, plastic hardening and deformation, and residual stress. All of these ingredients result in fatigue criteria evolutions: it is important to stress that the stamping process can have advantageous or disadvantageous consequences on the fatigue design. This is here highlighted on some examples, dealing with front and rear axles.
\end{abstract}

\section{Main axle safety part: Presentation and mechanical properties}

The studied part is a steel front axle cross member for a commercial vehicle. The material is assumed to be homogeneous and isotropic, with elastic-plastic behavior and isotropic hardening. The part geometry is shown in Fig. 1 and material properties are presented in the Table 1.

\section{Fatigue design}

Design is achieved by applying the Dang Van criterion, Eq. (1) [1, 2]. The macro-meso approach uses of the cumulated plastic strain at a mesoscopic scale as the damage variable.

$$
\max _{t}\left(\tau_{a}(\mathrm{t})+a p_{h}(\mathrm{t})\right) \leq b \quad \text { with } \quad \mathrm{a}=\left(\sigma_{t}-\frac{\sigma_{f}}{2}\right) \frac{3}{\sigma_{f}} \quad \text { and } \quad \mathrm{b}=\sigma_{t}
$$

The parameters $\mathrm{a}$ and $\mathrm{b}$ are function of the material fatigue limits in torsion, $\sigma_{t}$ and in alternated flexion, $\sigma_{f}$ as shown in Fig. 2.

This is an Open Access article distributed under the terms of the Creative Commons Attribution License 4.0, which permits unrestricted use, distribution, and reproduction in any medium, provided the original work is properly cited. 


\section{MATEC Web of Conferences}

Table 1. Mechanical properties of the front axle cross member.

\begin{tabular}{|c|c|c|c|c|c|c|}
\hline Material & $\begin{array}{c}\text { Young Modulus } \\
(\mathrm{MPa})\end{array}$ & $\begin{array}{c}\text { Poisson } \\
\text { coefficient }\end{array}$ & $\begin{array}{c}\mathrm{Rm} \\
(\mathrm{MPa})\end{array}$ & $\begin{array}{c}\text { Density } \\
\left(\mathrm{kg} \cdot \mathrm{m}^{-3}\right)\end{array}$ & $\mathrm{A} \%$ & $\begin{array}{c}\text { Isotropic hardening } \\
(\mathrm{MPa})\end{array}$ \\
\hline TRIP800 & 210000 & 0.3 & & 7800 & & $\sigma=488+862 \varepsilon^{0.24}$ \\
\hline
\end{tabular}

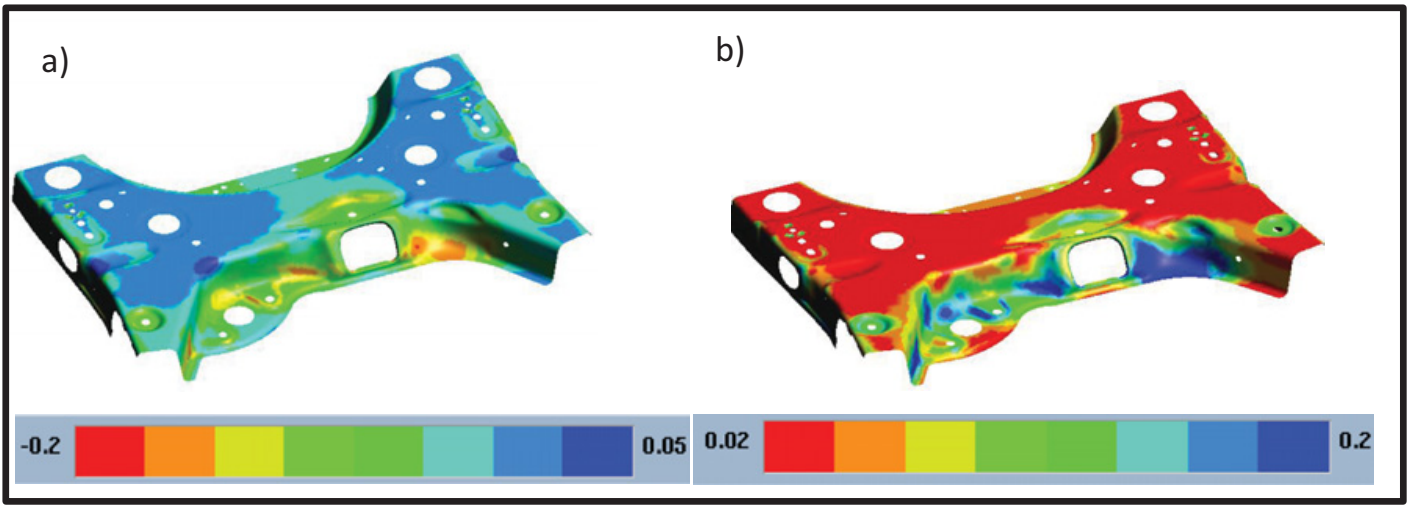

Figure 1. a) Thinning (\%) and b) plastic strain ( $\mathrm{mm} / \mathrm{mm})$ computed by [3].

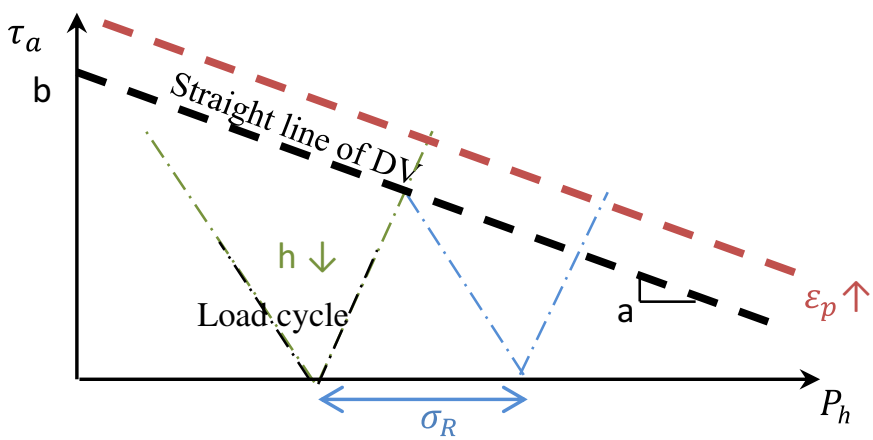

$\mathrm{h}$, thickness

$\varepsilon_{\mathrm{p}}$, plastic strains

$\sigma_{\mathrm{R}}$, residual

Figure 2. Influence of effect of stamped process.

\section{Influence of stamped process on fatigue design}

The stamping process does have influences on the part geometry and its mechanical properties, thus on fatigue design, as already discussed in [4]. Indeed, because of forming, plastics strains and residual stresses emerge (Fig. 1b). Moreover, a thickness reduction appears where the sheet is highly stretched, whereas thinning occurs where the material is restrained (Fig. 1a).

All these comments may be illustrated in the Dang Van framework (Fig. 2):

- the increasing of plastic strains moves up the Dang Van straight line according to the equation 2 where $\mathrm{A}$ is function of hardening;

$$
\frac{b}{b_{0}}=1+\mathrm{A} \varepsilon_{p}
$$

- the residual stresses shifts the load cycle along the horizontal axes, depending on traction (to the right) or compression (to the left);

- the thickness reduction emphasizes the load cycle amplitude. 
These three process effects may strongly affects fatigue design. On the one hand, there are expected to be taken into account for design reliability. On the other hand, these three effects offer opportunities to optimization.

\section{References}

[1] Dang Van K., Macro-micro approach in high-cycle multi-axial fatigue, McDowell DL, Ellis R, editors. Advances in multi-axial fatigue, ASTM STP 1191, Philadelphia, PA: ASTM, 1993, 120-30

[2] Papadopoulos IV, Fatigue limit of metals under multi-axial stress conditions: the microscopic approach. Technical Note No. I.93.101, Commission of the European Communities, Joint Research Centre, ISEI/IE 2495/93, 1993

[3] AutoForm OneStep, AutoForm Engineering GMBH, www.autoform.com

[4] M.L.Facchinetti, B.Weber, C.Doudard, S.Calloch, Taking into account the forming process in fatigue design computations. Fatigue Design, November 21-22, 2007 